Mara Alice Batista Conti Takahashi ${ }^{1}$ Célio Roberto Pizzi²

Eugênio Paceli Hatem Diniz ${ }^{3}$

\section{Nutrição e dor: o trabalho das merendeiras nas escolas públicas de Piracicaba - para além do pão com leite}

\author{
Nutrition and pain - cafeteria workers' job in a public school in \\ Piracicaba, Brazil - beyond bread and milk
}

${ }^{1}$ Socióloga do Centro de Referência em Saúde do Trabalhador de Piracicaba.

${ }^{2}$ Analista Pericial em Engenharia de Segurança do Trabalho da Procuradoria Regional do Trabalho de Campinas.

${ }^{3}$ Pesquisador da Fundacentro-MG e Professor do Curso de Especialização em Ergonomia da Universidade Federal de Minas Gerais/Universidade Metodista de Piracicaba.

Contato:

Mara Alice Batista Conti Takahashi

Rua Francisco de Assis, 983

Centro - Piracicaba-SP

E-mail:

maraconti_tak@yahoo.com.br
Recebido: 18/11/2009

Revisado: 31/05/2010

Aprovado: $14 / 06 / 2010$

\section{Resumo}

O estudo da atividade de trabalho das merendeiras escolares foi motivado pela alta incidência de casos de LER/DORT nesta categoria profissional. Em escola pública de Piracicaba-SP, no período de março de 2007 a março de 2008, procurou-se compreender as condições de execução do preparo e da distribuição das refeições com o objetivo de identificar os fatores de risco presentes na organização do processo de trabalho e na causalidade das LER/DORT, propondo-se, ao final, medidas de transformação. O método foi a Análise Ergonômica do Trabalho e seus procedimentos: observações gerais, filmagens, observações sistemáticas de variáveis previamente escolhidas e registros das verbalizações das trabalhadoras sobre o seu trabalho. Os resultados mostram a intensificação do trabalho decorrente de mudanças quantitativas e qualitativas da Merenda Escolar no Brasil sem o devido aporte do efetivo e a melhoria das condições operacionais. As principais recomendações foram: (1) mecanização parcial das atividades de higienização dos utensílios; (2) elaboração de um novo cardápio, com a participação das merendeiras, que considere a carga real de trabalho; e (3) reuniões mensais e semestrais para participação das merendeiras nas decisões que afetam o trabalho. Concluiu-se que compreender e superar as deficiências do trabalho das merendeiras, eliminando os seus agravos à saúde, constitui-se em estratégias vitais para alcançar os amplos objetivos desta política pública.

Palavras-chaves: merendeiras escolares; escola pública; LER/DORT; Análise Ergonômica do Trabalho.

Abstract
The study of activity of the work among cafeteria employees in Public School Sector
was motivated by high incidence of RSI/WRMD (repetitive strain injury/work
related musculoskeletal disorder) in this profession. After observing preparation
and distribution of meals in a public school in Piracicaba, São Paulo, Brazil, we
identifiedorganizationalandRSI/WRMD riskfactorsandproposed transformational
measures. The research was conducted from March 2007 to March 2008 according
to Work Ergonomic Analysis and its procedures: general observation, filming,
systematic observation and recording of workers' verbalizations on their jobs. The
results showed an intesification of work due to quantitative and qualitative changes
introduced in the school menus in Brazil, without an equivalent increase in staff
or improvement of operational conditions. Our main recommendations were:
partial mechanization of activities concerning cleansing of utensils; involvement
of workers in the development of a new menu, which would take into account
the staff's real workload; and monthly and biannual meetings as moments for
workers' participation in their job decision making process. We concluded that
understanding and overcoming school cafeteria workers'job deficiencies, as well
as eliminating risks to their health are vital strategies to reach the objectives of the
widespread national public policy on school meals.
Keywords: school cafeteria worker; public school sector; RSt/WRMD; Ergonomic

Keywords: school cafeteria worker; public school sector; RSI/WRMD; Ergonomic Work Analysis. 


\section{Introdução}

Este artigo descreve os resultados da Análise Ergonômica do Trabalho (AET) realizada com merendeiras das redes pública municipal e estadual de ensino do município de Piracicaba.

A presente análise é um relato de experiência de ações de prevenção e vigilância realizadas pelo Centro de Referência em Saúde do Trabalhador de Piracicaba (Cerest-Piracicaba), na empresa de terceirização de mão de obra para refeições coletivas, contratada pelo poder público municipal para complementar o efetivo de pessoal da Merenda Escolar e que, em curto período de tempo de contratação, passou a apresentar alta incidência de Lesões por Esforços Repetitivos/Doenças Osteomusculares Relacionadas ao Trabalho (LER/DORT) no seu quadro de merendeiras.

Na época do estudo, existiam 243 merendeiras com vínculo direto com a prefeitura municipal e 205 terceirizadas (sendo 10 trabalhadoras volantes para cobrir as faltas), num total de 448 trabalhadoras.

Segundo dados administrativos de maio de 2007, das 243 merendeiras vinculadas à prefeitura municipal, apenas 165 (68\%) estavam atuando na função, 67 (28\%) estavam readaptadas em outras funções por motivo de incapacidade para o exercício da função original (uma porcentagem elevada que por si já indica problemas referentes ao exercício da função) e 11 (4\%) estavam afastadas por licenças médicas. Ou seja, praticamente um terço da mão de obra estava ou esteve com problema de saúde em decorrência do trabalho.

O atendimento às merendeiras concursadas é realizado pelo Serviço Municipal de Segurança e Medicina do Trabalho (Sesmt) da prefeitura. O atendimento às merendeiras vinculadas à empresa de terceirização é da competência legal do Cerest-Piracicaba para as ações de investigação diagnóstica, nexo causal, assistência e reabilitação profissional. Destas, de 2003 a 2007, foram assistidas pelo serviço, 32 merendeiras de escolas públicas, ou seja, $15 \%$ do efetivo.

A reorganização no mundo do trabalho das últimas décadas caracteriza um conjunto de transformações e, dentre estas, a intensificação dos processos de terceirização de atividades dos serviços públicos.

A terceirização, na abordagem administrativa, é uma modalidade de contratação através da qual há um processo de transferência da responsabilidade pela execução de atividades de uma empresa ou instituição para outra empresa subsidiária, podendo incluir tanto as etapas do processo produtivo, ou atividades-fins, como os serviços de apoio, também denominados atividades-meio, como, por exemplo, os serviços das lavanderias, de limpeza, de manutenção, de nutrição, dentre outros (ZAMBERLAN; SIQUEIRA, 2005).
Ainda que estudiosos das áreas de planejamento e gestão defendam que a terceirização possibilita que a organização centre-se na realização de algumas ações, viabilizando a racionalização da produção e o consequente aumento da produtividade, Chillida e Cocco (2004), focalizando os serviços hospitalares, advertem que a modalidade tem sido mais uma tática de redução de custos pela exploração de relações precárias de trabalho.

A presente pesquisa encontrou, na escola estudada, uma situação combinada de merendeiras concursadas e terceirizadas, porém, igualmente submetidas às mesmas condições adversas de trabalho.

A demanda inicial, colocada pela gestão do departamento de merenda escolar do município, foi a de que havia falta de racionalização na distribuição das tarefas entre as merendeiras por existir apenas uma prescrição genérica do serviço, ficando a cargo da própria equipe a divisão das tarefas. A expectativa era a de que um manual de procedimentos, que definisse ergonomicamente as tarefas de cada funcionária e estabelecesse uma carga de trabalho mais equitativa e melhor distribuída ao longo da jornada, pudesse ser a solução definitiva para o problema do adoecimento por LER/DORT entre as merendeiras.

Entretanto, as primeiras observações gerais já indicaram uma reformulação da demanda pela identificação de que não se tratava de um fator comportamental, decorrente da má administração do tempo pelas merendeiras, mas sim, de que havia uma intensificação do trabalho em decorrência de expressivas modificações qualitativas e quantitativas na merenda escolar. Ao tradicional café com leite e pão com manteiga, geralmente servido uma única vez, foram incorporadas várias refeições diárias, de elaboração mais trabalhosa, com horários rígidos de fornecimento e observância das normas de higiene sanitária, sem correspondência no aumento do efetivo ou na incorporação de um novo turno de trabalho nem modificações substanciais nas condições de trabalho.

Estes fatores resultaram na diminuição do tempo disponível para o preparo e a distribuição das refeições, na eliminação da porosidade do trabalho e no uso mais intensivo dos membros superiores e inferiores das trabalhadoras durante um período de tempo maior, levando ao adoecimento por LER/DORT. Desse modo, constatou-se que a questão não poderia ser solucionada apenas por um manual de procedimentos e pela supervisão constante, como era a expectativa da coordenação.

A LER/DORT é uma doença ocupacional bastante estudada e bem esclarecida na sua relação entre as manifestações patológicas dos membros superiores e pescoço e as condições de trabalho (ASSUNÇÃO; VILELA, 2009). No entanto, na literatura nacional, são escassos os estudos ergonômicos que revelam a associação entre o trabalho de profissionais de alimentação e a LER/ DORT (LIMA et al., 1997; NUNES, 2000; SILVA; BRITO; ATHAYDE, 2001). 
De origem multifatorial complexa, as LER/DORT ocupam o primeiro lugar em afastamento do trabalho por doenças ocupacionais nos países industrializados e são produtos de um desequilíbrio entre as exigências das tarefas de trabalho e as capacidades funcionais individuais para responder a essas exigências. As características da organização do trabalho são as moduladoras de tais desequilíbrios, o que implica em medidas de transformação das condições geradoras do adoecimento.

A LER/DORT tem em sua causalidade os fatores de risco físicos e biomecânicos, tais como: a força e os esforços físicos realizados, a repetitividade de gestos e movimentos, as posições extremas e as vibrações de máquinas e equipamentos. Seu estabelecimento resulta da interação dos diversos fatores patogênicos citados, mas estes podem ser atenuados pela diminuição da amplitude, da frequência e da duração da exposição, contribuindo para a redução da incidência e da gravidade da doença (ASSUNÇÃ̃O; VILELA, 2009, p. 21).

A organização do trabalho das merendeiras é definida pela coordenação da Secretaria Municipal de Educação, entretanto, pauta-se nas diretrizes do Plano Nacional de Alimentação Escolar (PNAE) do Governo Federal, que define metas nutricionais de acordo com a faixa etária e o tempo de permanência na escola: para os alunos do Ensino Fundamental (7 a 14 anos), que permanecem na escola por meio período, deve ser suprido de $15 \%$ a $30 \%$ de suas necessidades nutricionais, o que é feito através de duas refeições diárias - café (da manhã ou da tarde) e merenda (que, ao contrário do que possa sugerir o nome, equivale a um almoço ou a um jantar); para as crianças do Ensino Infantil (0 a 6 anos), que permanecem na escola em tempo integral, devem ser supridas $65 \%$ de suas necessidades nutricionais, o que é feito através de quatro refeições diárias - café da manhã, almoço, café da tarde e jantar.

A partir de 1988, a merenda escolar foi estabelecida como direito constitucional, vindo a sofrer importantes transformações quanto ao seu conteúdo e sua operacionalização, entre as quais destacamos duas diretrizes que afetam a carga de trabalho das merendeiras: (1) o controle social é feito através dos Conselhos da Alimentação Escolar (CAE), formados por representantes da Secretaria Municipal da Educação, professores, pais de alunos, alunos e comunidade em geral, que têm como funções acompanhar e deliberar sobre a aplicação de recursos, a aquisição de alimentos, seu armazenamento, preparo e distribuição; (2) grande parte dos alimentos consumidos são in natura e devem ser adquiridos de pequenos produtores locais.

Para o cumprimento das metas nutricionais, a tradicional merenda escolar se transformou em refeições mais elaboradas, constituídas de, por exemplo, arroz, feijão, estrogonofe de frango e batata sautée, os quais acarretam um maior número de procedimentos, maior dispêndio de tempo no seu preparo e, por consequên- cia, o uso mais intensivo do sistema muscoloesquelético das merendeiras.

Do mesmo modo, foram incorporadas metas higiênicas à política de segurança alimentar brasileira. A manipulação dos alimentos, de acordo com as normas sanitárias, constitui objeto de fiscalização pública, acarretando, para as trabalhadoras, a necessidade de incorporação das novas tarefas, como clorar as verduras, as frutas, as canecas, os pratos, as colheres etc., representando um aumento importante no volume de serviço a ser executado diariamente.

Apesar do novo patamar de importância alçado pela merenda escolar, não se observaram investimentos em infraestrutura das cozinhas e incremento do efetivo de trabalhadoras.

É dentro desse contexto que este artigo se propõe a redescobrir o trabalho das merendeiras das escolas públicas, mostrando que impactos teve a reestruturação da merenda escolar no seu trabalho e na sua saúde.

Destaca-se que a LER/DORT no segmento das merendeiras não está circunscrita ao município estudado, mas, pela sua disseminação e magnitude, configura-se como um problema de saúde pública no Brasil (NUNES, 2000, p. 84).

\section{Método e procedimentos}

A Análise Ergonômica do Trabalho (AET) é um método de abordagem da Ergonomia Francesa que se propõe a estudar e contribuir para a adaptação do trabalho ao homem (WISNER, 1996).

A ergonomia busca compreender as situações de trabalho, a inseparável relação entre as condições de execução do trabalho e as atividades desenvolvidas pelos trabalhadores, sendo estas o foco privilegiado de análise.

Nesta perspectiva, objetiva-se conhecer o trabalho real dos homens em situações concretas de trabalho, o que exige apreender um duplo conhecimento: o comportamento do trabalhador enquanto trabalha e os determinantes das condições em que ele trabalha (LIMA, 1997).

Segundo Guérin et al. (2001), a AET deve ser desenvolvida por meio das seguintes etapas: a) a análise da demanda - que consiste na definição do problema a ser analisado e na negociação com os atores sociais envolvidos, implicando, na maior parte das vezes, reformulação da demanda inicial; b) a análise do funcionamento da organização - sua história, forma de gestão do trabalho, organograma e outras questões referentes ao seu contexto socioeconômico e político; c) a análise da tarefa - o que a organização prescreve para os trabalhadores realizarem e quais as condições ambientais, técnicas e organizacionais desta realização; d) a análise da atividade - o que os trabalhadores efetivamente realizam na execução das tarefas, como realizam e o 
porquê; Nesta etapa, há uma descrição sistemática de variáveis observadas e apreendidas por verbalizações dos trabalhadores na execução concreta do trabalho; e) elaboração do pré-diagnóstico - levado junto aos trabalhadores para a autoconfrontação do relatório e sua validação; f) redação do Diagnóstico e das Recomendações finais, onde são colocados os princípios gerais e as orientações práticas para a concepção de uma nova organização do trabalho, com vistas à melhoria das condições de trabalho e à prevenção de novas ocorrências.

Dentre as etapas de desenvolvimento do método, merece destaque a apreensão das verbalizações dos trabalhadores, uma vez que a atividade não consiste apenas de gestos, que são observáveis, mas os raciocínios, do tratamento das informações, da comunicação entre os pares e do planejamento das ações, que só podem ser apreendidos por meio das explicações dos trabalhadores (GUÉRIN et al., 2001, p. 165).

Para a realização da AET, foi escolhida uma Escola Municipal de Ensino Infantil e Fundamental (EMEIF), situada em um bairro periférico da cidade. Os critérios de escolha foram: (1) unidade que reunisse os dois níveis de ensino - Infantil e Fundamental - e, portanto, os dois tipos de cardápio; (2) equipe mista, composta por merendeiras contratadas diretamente pela Prefeitura e terceirizadas.

Sob os princípios metodológicos citados, adotaram-se os seguintes procedimentos: três observações gerais, quatro observações sistemáticas e uma reunião com o grupo das merendeiras para a validação do diagnóstico e das recomendações propostas.

O estudo foi realizado no período de março de 2007 a março de 2008, totalizando dez meses de trabalho de campo devido às interrupções ocorridas nos meses de dezembro e janeiro, meses referentes às férias escolares que são utilizados pela coordenação da Merenda Escolar para reuniões técnicas de capacitação.

No conjunto, quatro merendeiras foram observadas, anotadas as suas verbalizações, totalizando um trabalho de campo de 60 horas. Foram realizadas 4 horas de filmagens em situações reais de trabalho - que foram, posteriormente, analisadas e incorporadas ao diagnóstico, servindo de apoio visual para a autoconfrontação com as trabalhadoras e validação dos resultados.

A aplicação da metodologia descrita observou rigorosamente os princípios éticos: (1) consentimento livre e esclarecido dos sujeitos observados em atividade; (2) confidencialidade, privacidade e proteção da imagem, garantindo-se o anonimato das verbalizações; (3) respeito aos valores culturais, morais, religiosos e éticos, bem como aos hábitos e costumes dos trabalhadores envolvidos; (4) relevância social da pesquisa, ou seja, destinação sócio-humanitária; (5) validação dos resultados com os trabalhadores e a gerência (ABERGO, 2003).

\section{Resultados}

\section{Tempos modernos: as atividades de trabalho das me- rendeiras}

O efetivo responsável pela elaboração da merenda escolar é majoritariamente feminino, contando com apenas cinco trabalhadores do sexo masculino (1\% do efetivo, incluindo as terceirizadas).

O sistema da Merenda Escolar no município estudado atende 213 unidades constituídas de escolas estaduais, municipais, centros de atendimento socioeducativo, instituições filantrópicas e programas de educação de jovens e adultos.

O cardápio é elaborado por uma nutricionista e é padronizado para toda a rede escolar do município. Sua elaboração obedece aos seguintes critérios: (1) faixa etária dos alunos atendidos, (2) sua jornada diária na escola, (3) objetivos nutricionais do Plano Nacional de Alimentação Escolar e (4) custo das refeições. As alterações de cardápio, condicionadas à prévia autorização da coordenação, somente ocorrem em situações de desabastecimento de gêneros e/ou redução drástica do efetivo.

A escola selecionada para a análise é de médio porte, com 313 alunos matriculados, dos quais 103 frequentam o Ensino Infantil, composto pelo Berçário e o Maternal, e 210, o Ensino Fundamental.

A equipe responsável pela elaboração da merenda escolar é composta de quatro merendeiras. Além dessa equipe, existe mais uma trabalhadora denominada lactarista, que, por atender exclusivamente o Berçário, em cozinha separada, não participou deste estudo.

O Ensino Infantil, excluindo-se o Berçário, é constituído de 75 crianças que permanecem na escola das 7 h30 às 17h. Elas tomam quatro refeições por dia: café da manhã, almoço, café da tarde e jantar (merenda).

O Ensino Fundamental possui 210 alunos, distribuídos em dois turnos. No turno da manhã, 80 alunos permanecem na escola das $7 \mathrm{~h}$ às $12 \mathrm{~h}$ e têm duas refeições diárias: café e almoço. No turno da tarde, 130 alunos permanecem na escola das $12 \mathrm{~h} 10$ às $17 \mathrm{~h}$ e também têm duas refeições diárias: café e jantar (merenda).

As quatro merendeiras que tiveram sua atividade analisada preparam 8 refeições diárias, num total de 720 unidades de refeição para atendimento de todos os alunos. Assim, ao longo de um dia de trabalho, a equipe precisa preparar e servir 8 refeições, constituídas de:

- 4 cafés (2 no turno da manhã e 2 no turno da tarde) compostos de leite em pó batido com chocolate e servido com biscoito ou pão com margarina;

- 1 almoço, com cinco pratos (arroz, feijão, carne, frango ou ovos, legume ou verdura cozida e salada crua); 
- 3 merendas que, a despeito do significado tradicional, ${ }^{4}$ assemelham-se praticamente a outro almoço ou a um jantar, pois se compõem de uma refeição bem elaborada como, por exemplo, risoto de frango com legumes e salada mista crua ou sopa de feijão com macarrão, carne e legumes e salada mista crua.

Percebe-se que, de merenda, restou apenas o nome. A verbalização de uma das trabalhadoras ilustra bem um dos efeitos dessa reestruturação: "O pior mesmo é a correria, a gente mal chega e já está correndo, não pára nunca...”

Para preparar essas refeições, a divisão de tarefas é realizada por um acordo entre o grupo, uma vez que não existem tarefas pré-determinadas, pormenorizadas e permanentes para cada merendeira.

Quando o expediente de trabalho começa, as merendeiras dão início a uma série de ações para preparar as refeições que serão servidas ao longo do dia. Assim, durante o processo do preparo do café da manhã, observam-se ações simultâneas de preparo do almoço e da merenda. O preparo de uma refeição termina e inicia-se quase que imediatamente o procedimento de servir os alunos e a seguir o recolhimento e a higienização dos utensílios utilizados. O ritmo de trabalho de cada uma das merendeiras é incessante, agindo quase como autômatas, mas que estão, a todo o momento, colocando seu saber em prática para atender às metas nutricionais de higiene e às exigências temporais dos horários precisos e fixos.

$\mathrm{O}$ expediente inicia-se às $6 \mathrm{~h}$ da manhã com uma merendeira. Às 6 h30 chegam as outras três merendeiras. Em menos de 1 hora, elas se encarregam de coar o café para os 33 funcionários da escola, preparar 120 pães e 16 litros de leite com chocolate para o café das $7 \mathrm{~h}$ dos alunos do Ensino Fundamental, doravante denominado Escola, e, na sequência, às $7 \mathrm{~h} 30$, para os alunos do Ensino Infantil, doravante denominado Creche, denominações dadas pelas merendeiras.

A tarefa de preparo dos pães envolve cortá-los no sentido do comprimento, passar margarina sobre os dois lados, cortar o pão ao meio e colocar os pedaços em uma bacia plástica. O corte ao meio é adicional, uma vez que é previsto um pão para cada criança, porém, trata-se de uma atitude de zelo do grupo para evitar desperdício, porque algumas crianças não comem um pão inteiro.

Esta tarefa é realizada em postura em pé, com os braços em posição elevada, sem sustentação, com movimentos em ciclos curtos (17 segundos cada), o que contribui para sobrecarregar a musculatura dos membros superiores e inferiores.

O mesmo padrão de movimentos foi observado por ocasião da distribuição do leite com chocolate. A merendeira utiliza uma concha para pegar a mistura num canecão, para depois encher cada uma das 150 canecas dispostas em uma bandeja, que é colocada sobre uma mesa. As próprias crianças se servem, pegando as canecas e os pães. Depois de tomar o leite, as crianças devolvem as canecas, deixando-as sobre a bancada.

Nesta operação foi observada uma exigência temporal a mais, que demanda um tempo não prescrito. Após o preparo, uma leiteira com seis litros, duas bandejas com as canecas e uma bacia com pães são transportados num carrinho manual para o refeitório da Escola, distante aproximadamente 50 metros da cozinha. No refeitório, o material é colocado numa mesa de apoio. Terminada a refeição das crianças, os utensílios são recolhidos para o carrinho e transportados de volta à cozinha.

Movimentos repetitivos e os braços em elevação são observados também durante o recolhimento e a lavagem das canecas, o que ocorre imediatamente após o término da distribuição. Dois tipos de constrangimentos obrigam à lavagem imediata das canecas: (1) a quantidade de canecas supre a necessidade de apenas uma refeição, e (2) é impossível acomodá-las sobre a pia, já que estariam ocupando espaço necessário ao pré-preparo das refeições seguintes.

Ao mesmo tempo em que estas atividades de pré-preparo, distribuição e higienização dos utensílios do café da manhã estão sendo desenvolvidas, duas merendeiras já iniciaram as ações de descascar, cortar e picar os legumes, as verduras, as frutas e as carnes que serão utilizadas na merenda da Escola e no almoço da Creche.

O tempo prescrito para preparar a merenda é de três horas (que será servida rigorosamente às 9h30) e de quatro horas para preparar o almoço (servido às 10h30), o que demanda que os dois tipos de refeição sejam preparados simultaneamente. Destaca-se que, durante o momento final de cocção do almoço da Creche, as trabalhadoras ainda se encontram ocupadas com as tarefas de servir a merenda da Escola, recolher e higienizar os utensílios dessa refeição, tomando o cuidado de não deixar o almoço queimar ou passar do ponto.

Nas atividades de pré-preparo dos alimentos, notamse, mais uma vez, movimentos rápidos e de precisão, em ciclos curtos, com os braços suspensos e sem apoio. A tarefa de descascar, cortar e picar um a um os legumes e as frutas e agrupar e picar as folhas de verduras exige uma utilização quase que permanente dos mesmos grupos musculares dos membros superiores, inferiores e da coluna, que são demandados ao longo de toda a jornada de trabalho. Ou seja, as tarefas variam ao longo do dia, mas as exigências posturais e musculares, não.

Diante da pluralidade e da simultaneidade das tarefas e dos horários rígidos em que as refeições devem estar prontas, constata-se que as merendeiras estão submetidas a um trabalho de alta densidade (WISNER, 1993) e sem poros que possam recompor o desgaste muscular, ou como elas dizem: "Aqui tudo tem que descansar [referindo-se à cloração]: os pratos, as maçãs... menos as merendeiras". 
Mas, como é possível viabilizar o trabalho diante da pressão temporal e da multiplicidade de tarefas que precisam ser realizadas de forma simultânea? Observou-se que, para responder a esses desafios, as merendeiras se sustentam no apoio do coletivo da equipe. É graças a este coletivo que o processo de produção da merenda é realizado de acordo com o previsto, apesar das dificuldades vivenciadas. Cada uma faz o que precisa fazer, no momento certo e no tempo certo, sem precisar de alguém que fique solicitando ou fiscalizando-as.

\section{O prato principal: muito trabalho e pouco tempo}

Todos os pratos do almoço e da merenda têm como base carne ou frango. As operações de limpeza e de corte da carne e do frango são indicadas pelas merendeiras como muito difíceis de serem executadas, por isso, estas atividades precisam ser antecipadas no dia anterior, no período da tarde: "É pesada, é cansativa! A posição na pia é ruim... você fica direto ali, até mais de uma hora... Quando você sai dali, está quebrada”, disse uma merendeira, e todas as outras concordaram.

Como a carne licitada deveria ser entregue picada e limpa, não há tempo prescrito para esta tarefa. O trabalho das merendeiras seria apenas o de retirar a carne do congelamento meia hora antes de realizar o seu preparo. No entanto, elas precisam retrabalhar a carne ou o frango, melhorando a limpeza e o corte: "A carne é comprada picada, mas é muito mal picada, precisamos picar em pedaços menores e limpar bem, tirar nervuras e gorduras, senão as crianças não comem”.

O retrabalho das carnes mostra a preocupação das merendeiras com as crianças, esmerando-se no pré-preparo dos alimentos. Levando-se em conta o montante de $20 \mathrm{~kg}$ de carne e $30 \mathrm{~kg}$ de frango consumidos numa refeição, essa ação também resulta em intensificação do trabalho e diminuição da porosidade, uma vez que se trata de um tempo e uma tarefa não prescritos.
A incorporação de um ato particular de cuidado também foi observada no preparo da couve, ainda que à custa da sobrecarga do seu corpo. Ao utilizar o multiprocessador para cortar a couve, a merendeira não ficou muito satisfeita com o resultado:

\begin{abstract}
Ela fica bem machucada! Se você quiser que ela fique mais bonitinha (mais firme e uniforme, complemento nosso), você tem que cortar na mão. Quando a gente tem um pouco mais de tempo. a gente corta na mão, isto quando a gente não está muito cansada também, senão vai no processador. O final tem que ser cortado na mão, a máquina não pega quando é pouca folha.
\end{abstract}

A atividade de distribuição do almoço da Creche (5 pratos: arroz, feijão, frango, couve e salada crua), para 56 alunos presentes no dia, envolveu mais esforço repetitivo e postura contraída para manter os braços em elevação. Três merendeiras executaram o serviço: uma merendeira realizou cerca de 120 movimentos para retirar o arroz e o feijão das vasilhas e colocar nos pratos; a segunda cerca de 180 movimentos para colocar o frango e a couve (ambas por vinte minutos); e a terceira merendeira cerca de 60 movimentos para colocar a salada crua, mas que, por permanecer sozinha mais dez minutos servindo aos vários alunos que repetiram, foram adicionados pelo menos mais 30 movimentos. Enquanto o almoço era servido, a quarta merendeira iniciara a lavagem das panelas e dos utensílios que haviam sido utilizados no seu preparo e, na sequência, mais duas merendeiras se incorporaram à lavagem de pratos e colheres que retornavam da distribuição (Quadro 1).

A cloração obrigatória por 20 minutos dos utensílios, pratos, talheres, antes de serem utilizados, torna-se mais uma dificuldade para o andamento do serviço, aumentando a densidade do trabalho. O fogão é limpo todos os dias, duas vezes por dia, no final das refeições de cada período.

Quadro 1 Crônica da atividade das merendeiras - período da manhã

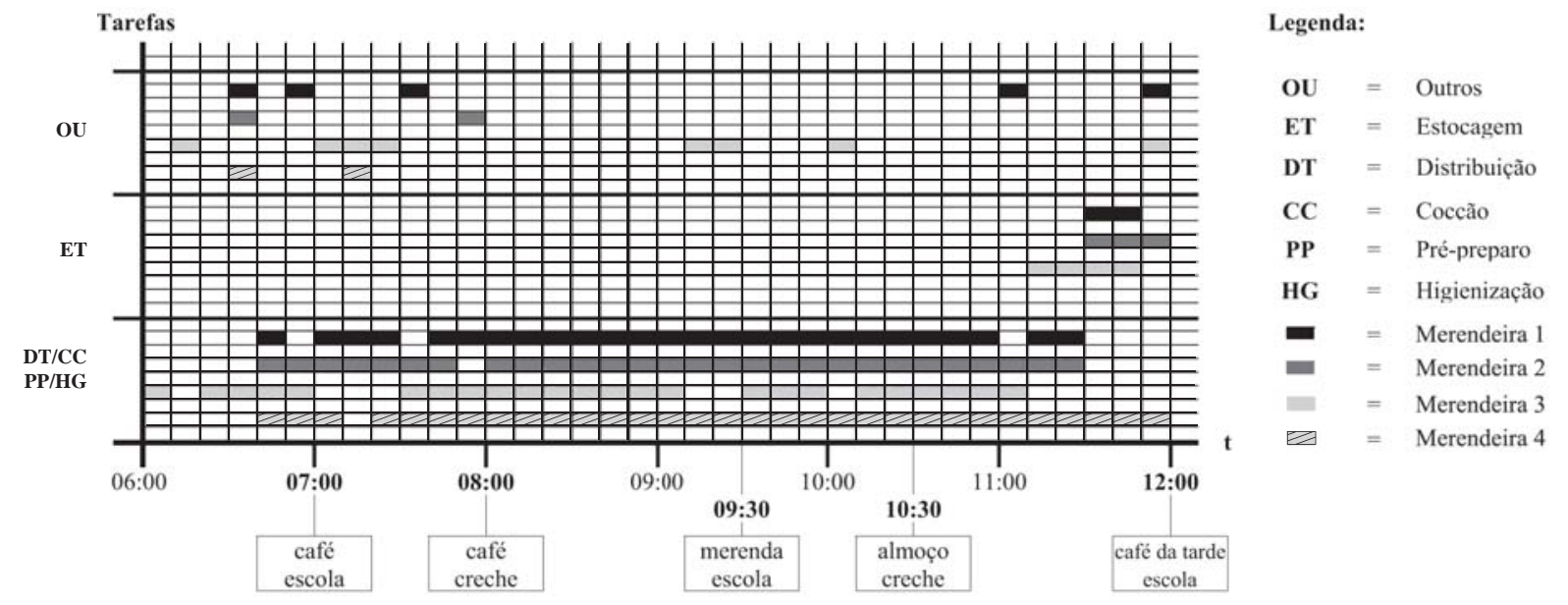


O almoço das merendeiras ocorreu entre $11 \mathrm{~h}$ e $12 \mathrm{~h}$. Elas almoçam uma de cada vez, pois, na cozinha, não há interrupção das atividades. Elas se revezam e imediatamente já vão iniciando o preparo das refeições da tarde ao mesmo tempo em que preparam o leite com chocolate para o café da tarde.

A necessidade de resfriar um pouco os pratos quentes é outro fator que também contribui para reduzir ainda mais o tempo real disponível no processo de elaboração da merenda. Alguns pratos demandam quase 30 minutos para esfriar até o ponto de poderem ser servidos sem apresentar risco de queimadura às crianças:

Temos medo que as crianças derrubem comida nelas e se queimem com polenta, com sopa. Por isso, temos que desligar um pouco antes. Quando não dá, fazemos um resfriamento: tiramos do panelão, colocamos numa panela menor e colocamos numa bacia com água, para deixar a comida no ponto da criançada comer sem perigo de se queimar.

Esse cuidado não se deve apenas à prevenção de acidentes, há nessa ação uma preocupação com a nutrição e com o lazer das crianças, ainda que acarrete mais trabalho à equipe:

Se a gente oferecer a comida muito quente, a criançada não come, porque eles não têm paciência de esperar esfriar, eles querem também brincar no intervalo. Se a gente serve no ponto, eles comem tudo e depois ainda vão brincar.

As merendeiras consideram o período da tarde menos atribulado que o da manhã, devido ao cardápio único (merenda) tanto para a Escola (turno da tarde) quanto para a Creche (jantar). O prato preparado com todos os ingredientes colocados em uma única panela suprime a necessidade de temperar, mexer e vigiar a cocção de várias panelas ao mesmo tempo, como acontece no período da manhã. Não obstante, o volume dos procedimentos de pré-preparo - cozinhar o feijão, descascar, cortar e picar legumes, cozinhar e desfiar a carne - é novamente repetido e permanece o mesmo em termos de volume de serviço. Observa- -se, porém, um alívio nas atividades de lavagem pela redução do número de panelas (Quadro 2).

A pequena porosidade do período da tarde, todavia, é preenchida pela antecipação de tarefas das refeições do dia seguinte, como, por exemplo, a escolha dos grãos, o preparo do tempero básico (alho e cebola in natura passados no liquidificador) e o corte e a limpeza das carnes. A regulação adotada pelas merendeiras - utilizar a pequena porosidade do período vespertino para antecipar tarefas futuras - e a inexistência de pausa no horário de almoço comprometem uma possível recuperação muscular.

\section{Outras tarefas - uma "pitada" a mais no aumento da densidade do trabalho}

Nas tardes das terças e quintas-feiras, as merendeiras recebem os gêneros perecíveis, entregues pelos fornecedores. Essa tarefa envolve receber, conferir, separar e estocar, comprometendo a preciosa antecipação do preparo da merenda do dia posterior:

Este dia é difícil, você tem que receber, conferir, guardar [...] os legumes, e as frutas ainda dão para esperar um pouco, mas o açougue não dá [porque são alimentos que não podem ficar muito tempo fora do congelador], você tem que parar tudo que está fazendo para fazer isto.

Compete ainda às merendeiras realizar o controle do estoque dos produtos armazenados. Essa tarefa exige que, no início de cada mês, uma merendeira preencha duas fichas que são enviadas à Coordenação da Merenda Escolar: a primeira delas é referente ao consolidado mensal do número de alunos presentes por classe e a segunda é referente ao consolidado mensal da retirada de gêneros não perecíveis do depósito. Estes números devem estabelecer uma relação de coerência e servem de base para a solicitação dos insumos para o mês. Qualquer discrepância deve ser justificada e pode resultar em críticas de desperdício.

Quadro 2 Crônica da atividade das merendeiras - período da tarde

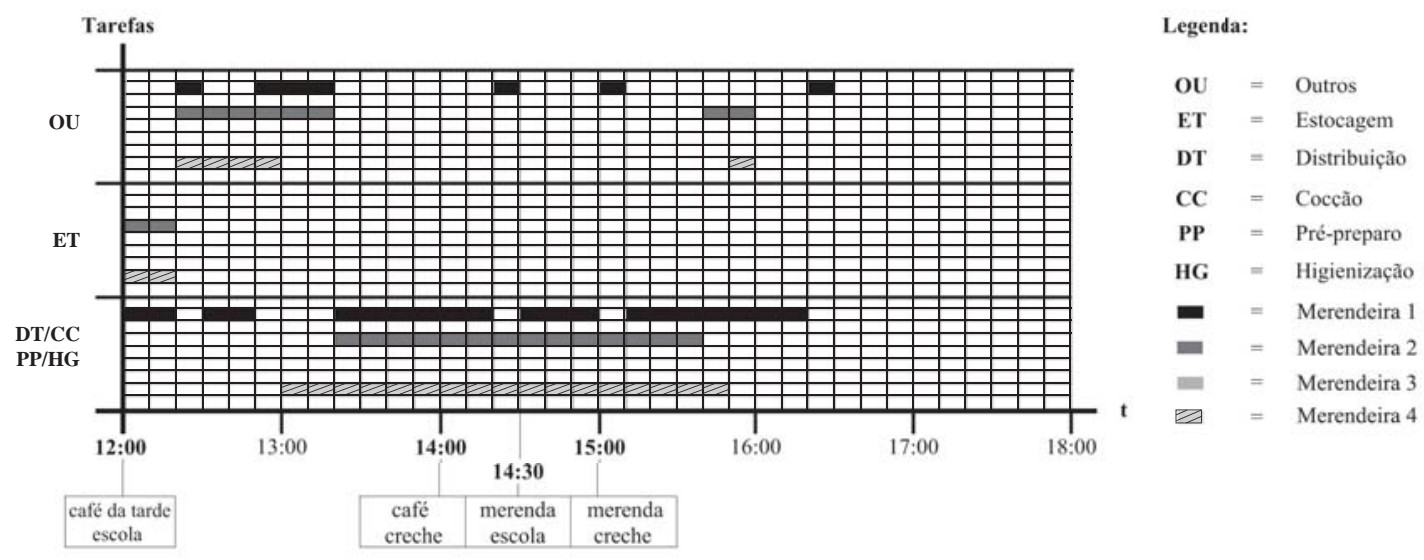


Além disto, a tarefa tem forte repercussão sobre a carga de trabalho das demais merendeiras. No caso do controle de estoque, por exemplo, é como se no período respectivo faltasse uma das integrantes do grupo no preparo da merenda, ou seja, é como se nesse período houvesse uma redução de $25 \%$ no efetivo da cozinha e sem direito a contar com o apoio da merendeira volante, da empresa terceirizada.

\section{Cronologia de uma orquestra afinada}

Ainda que pesem todos os constrangimentos apresentados e o ritmo intenso que envolve um dia de trabalho, o que se percebe é que as merendeiras trabalham como músicos de uma orquestra afinada, mas sem um maestro que as coordene nos movimentos e momentos da ação. Nesse tênue equilíbrio entre corpos, tempos e metas nutricionais alimentares, a experiência e o companheirismo do coletivo de trabalho não deixam o "caldo entornar" nem a música desafinar. Em silêncio, cada uma sabe o que fazer, quando fazer e o momento de dividir a carga de trabalho da colega ao lado.

Os Quadros 1 e 2 reproduzem graficamente a crônica da atividade das merendeiras coletada através da observação sistemática ao longo de um dia típico de trabalho (quinta-feira).

Observando-os, percebe-se que, em alguns momentos, o grupo se concentra numa dada tarefa ("força-tarefa”), com o propósito de abreviar o tempo gasto na sua realização. Como exemplos em destaque no quadro: o ocorrido na atividade de distribuir o almoço aos alunos da Creche, no intervalo das 10 h30 às 10h50; na atividade de lavagem de pratos e talheres servidos nessa mesma refeição, no intervalo das $11 \mathrm{~h}$ às $11 \mathrm{~h} 30$; e na tarefa de estocar os gêneros recebidos no dia, no intervalo das 11 h30 às 11 h50, entre outros. No período da tarde, foi observado que a mesma regulação é utilizada pelo grupo em alguns momentos.

A cronologia e os resultados apresentados até o momento mostram que não há falta de racionalização na distribuição das tarefas, como era pensado pelos gestores. Ao contrário, as merendeiras trabalham com a sincronia de uma orquestra. As estratégias desenvolvidas pelo coletivo de trabalho, além de viabilizar os propósitos do setor, possibilitam ao grupo lidar com as variabilidades e os constrangimentos impostos pela rigidez dos horários e pela escassez de tempo durante a jornada.

\section{Instrumentos e meios de trabalho: o saber não va- lorizado}

Como a questão do adoecimento por LER/DORT entre as merendeiras está reconhecida pelo poder público desde 2003, algumas medidas já foram adotadas com o propósito de conter o adoecimento, tais como: a reforma da estrutura física das cozinhas, a aquisição de utensílios mais leves e de fácil higienização, a substituição de equipamentos manuais por equipamentos elétricos, a facilitação dos cardápios e a complementação do quadro funcional com mão de obra terceirizada.

Entretanto, o grupo se queixou de não ter participado da elaboração do projeto da reforma da cozinha: "Nós opinamos muito pouco na reforma da cozinha, porque a gente estava ocupada o tempo todo e não dava para acompanhar a obra”.

Na avaliação das merendeiras, alguns "gargalos" operacionais poderiam ter sido evitados:

Se tivesse mais uma cuba na lateral (da pia), acho que resolveria o nosso problema de ter que lavar logo em seguida, para não atulhar a pia que a gente usa para preparar os alimentos.

O sol da tarde incide frontalmente na janela da cozinha, causando grande desconforto às merendeiras: "Este sol da tarde na pia dá uma fadiga! Já pedimos para colocar um toldo, mas eles disseram que não pode”.

Os equipamentos elétricos - liquidificador e multiprocessador, partes do projeto de modernização das cozinhas - são aceitos como instrumentos que ajudam muito, mas que dão muito trabalho na limpeza: "Gasta muito tempo para limpar [o multiprocessador], demora muito e, como aqui falta tempo, a gente acaba usando o manual mesmo".

Houve uma queixa generalizada em relação às facas e aos afiadores. As facas são consideradas ruins e não são apropriadas às tarefas:

As facas de cabo de madeira são melhores, mas eles sempre compram as de cabo de plástico branco... porque custam menos, eu acho [...] mas são ruins.

Para mexer a polenta, é usada uma pá de plástico, que tem um cabo mais comprido que as colheres convencionais e, por isso, é mais adequada, pois possibilita manter o braço mais distante da fervura. Por outro lado, esse utensílio é bastante pesado (400g), provocando cansaço e dores nos braços.

Foram observadas algumas diferenças entre os uniformes usados pelas merendeiras da prefeitura - bermuda branca e camiseta, e o uniforme da merendeira terceirizada - um vestido de brim grosso e um avental de plástico, inadequado para o clima local. Elas comentam:

O uniforme é ruim, o tecido é muito grosso, esta manga enrosca na maçaneta da porta, eu fico com o braço roxo porque prende... Eles falam que é para a gente se parecer com as mães e avós que cozinhavam bem... mas que adianta se ele incomoda, atrapalha, e pode até causar um acidente. (merendeira da empresa terceirizada)

Sobre o aumento no quadro de merendeiras da escola para diminuir a densidade do trabalho e consequentemente a correria, uma delas respondeu negativamente e as outras concordaram com a resposta: "Se colocar mais gente nesta cozinha pequena, vamos trombar uma na outra. É preciso outra cozinha, com outra equipe”. 


\section{Decisões centralizadas: efeitos sobre o coletivo}

O grupo todo se ressente por não poder participar das decisões que influem diretamente no seu trabalho, sejam decisões tomadas pela coordenação da merenda escolar, sejam decisões da direção da escola.

Dois exemplos são significativos: (1) a diretora da escola deslocou as refeições dos alunos da Escola para outro refeitório, distante aproximadamente $50 \mathrm{~m}$ da cozinha, o que acarretou o aumento das tarefas de distribuição dos cafés e das merendas dos dois turnos: carregar todo o material a ser utilizado num carrinho, transportar até o refeitório, descarregar, arrumar sobre a mesa antes de iniciar a distribuição; feita a distribuição, retirar todo o material da mesa, carregar o carrinho, transportar até a cozinha, descarregar o material colocando-o sobre a pia para a lavagem. A mudança gerou ainda maior demanda de tempo, o qual é bastante exíguo; (2) a substituição de pratos plásticos por pratos de vidro, devido ao aumento no peso dos pratos, resultando em maior dificuldade na distribuição das refeições e maior esforço físico na lavagem.

Percebeu-se, contudo, através das verbalizações que, além das dificuldades de ordem física, houve um componente emocional importante, uma vez que elas não foram chamadas a opinar sobre esta mudança:

O grande problema é que eles [as chefias responsáveis pela concepção do trabalho] sempre se esquecem das merendeiras [...] eles só lembram da gente na hora de comer [...] depois que comem, esquecem de novo.

Estes sentimentos demonstram, em última análise, a divisão social do trabalho: de um lado, aqueles que são autorizados a concebê-lo e a organizá-lo e, de outro lado, excluídos do processo decisório, aqueles que cumprem as tarefas. Este fato reflete uma situação muito comum no mundo do trabalho, pois, de um modo geral, os organizadores da produção e do trabalho prescrito não valorizam o saber tácito daqueles que o executam.

A assimetria presente nas relações de trabalho é produto de uma divisão entre "os que planejam e os que fazem", característica do modelo tecnicista dominante, em que o objetivo de mudança se dá sempre através de transmissão autoritária de normas (COSTA; RIBEIRO; RIBEIRO, 2001). Por conhecerem muito bem os problemas que enfrentam no cotidiano, as merendeiras anseiam poder participar mais das decisões que afetam o seu trabalho. Entretanto, elas quase não têm espaço para a sua expressão e, quando têm, como, por exemplo, nas visitas da supervisão técnica, que ocorrem uma vez ao mês, sentem que falam no vazio, pois as suas queixas e sugestões nunca são ouvidas, o que resulta num sentimento de desvalorização que afeta a saúde dessas trabalhadoras.

Com relação aos programas de capacitação que acontecem duas vezes por ano, durante o período das férias escolares, nos quais são reunidas todas as merendeiras da rede escolar do município, terceirizadas e da prefeitura, identificou-se que seu conteúdo está estritamente voltado para a transmissão de conhecimentos nutricionais sobre os alimentos, as formas adequadas de seu preparo, as normas higiênico-sanitárias e outros assuntos que a coordenação julga ser de interesse das merendeiras. Perde-se dessa forma um importante momento para ouvir as merendeiras e encontrar coletivamente soluções mais eficazes para os problemas de saúde do efetivo de trabalhadoras.

\section{Diagnóstico}

Os dados confirmam que a intensificação do trabalho das merendeiras é devido às expressivas modificações qualitativas e quantitativas no cardápio, estabelecidas por diretrizes macropolíticas da merenda escolar no Brasil, e não a uma questão relacionada à má administração do tempo e das tarefas por parte das trabalhadoras.

Nota-se que as merendeiras suportam os impactos das decisões tomadas pelo controle social, mas não participam de suas deliberações. Da mesma forma, os membros do Conselho da Alimentação Escolar (CAE) não participam dos problemas que afetam o processo de elaboração dos cardápios escolhidos. Assim, decisões como aquisição de produtos mais baratos e/ou de elaboração difícil refletem sobremaneira na carga de trabalho das merendeiras.

Ao realizar a análise ergonômica do trabalho em um restaurante universitário, Lima et al. (1997) constataram que:

O cardápio é o determinante essencial do processo produtivo, estruturando o conjunto de decisões que, colocadas em prática, possibilitarão o preparo diário das refeições, mas que também irão determinar grande parte das exigências do trabalho: [...] a composição do cardápio não resulta da soma aleatória de diversos tipos de pratos, mas é conseqüência de um conjunto de intenções e compromissos que buscam primordialmente atender ao usuário, quer do ponto de vista calórico-nutricional, quer do ponto de vista do paladar, buscando, da mesma forma, atender a critérios de custo. Em última análise, o cardápio é o ponto de convergência das relações entre a direção [...], os trabalhadores e os usuários, tendo implicações importantes nas restrições impostas aos responsáveis pela sua elaboração e execução. (LIMA et al., 1997, p. 147-148)

Na organização do processo de trabalho da merenda escolar não é diferente. O cardápio, concebido pela organização central sem a participação das merendeiras, é o principal determinante do volume das tarefas a serem executadas e do grau de dificuldade da sua execução.

Analisando os cardápios elaborados pela coordenação, constatou-se que, para atingir os objetivos nutricionais e de higiene, eles passaram por profundas transformações qualitativas e quantitativas. Ao tradicional café com leite e pão com manteiga foram incorporadas verdadeiras refeições, compostas de legumes, verduras, frutas, proteínas e carboidratos. Entretanto, o 
impacto dessa transformação nutricional não foi acompanhado de mudanças significativas no efetivo de merendeiras, na infraestrutura das cozinhas. O novo cardápio passou a exigir muito mais do corpo e da mente das trabalhadoras, em ritmo muito maior, durante mais tempo ao longo da jornada.

Além disso, a junção dos dois níveis de ensino representou, na prática, a junção de dois cardápios distintos, num mesmo espaço de tempo, aumentando ainda mais a pressão sobre o trabalho. Na cozinha, observou-se um maior volume e sobreposição de tarefas realizadas, reforçamos, no mesmo espaço de tempo, no mesmo espaço físico, pelo mesmo efetivo e praticamente com as mesmas condições materiais.

A modificação do cardápio da merenda escolar não resultou na incorporação de um novo turno de trabalho que pudesse suportar as transformações realizadas. Para agravar, o tempo real disponível tornou-se menor que o tempo prescrito em razão do trabalho gerado pelas condições dos produtos adquiridos (carne, frango, legumes e verduras in natura), pela necessidade de resfriamento dos pratos quentes, pelo transporte e distribuição parcial noutro refeitório e pela incorporação de tarefas estranhas à função de merendeira, tais como fazer a faxina geral da cozinha e responder pelo controle, recebimento e armazenamento dos gêneros alimentícios.

Como os horários prescritos para servir as oito refeições diárias são rígidos, pois obedecem aos intervalos entre as aulas, e o tempo disponível entre as refeições é exíguo, a regulação adotada pelas trabalhadoras foi de elaborar as diversas refeições simultaneamente. As tarefas estranhas, incorporadas à função de merendeira, são realizadas no meio desse tempo, durante o processo de preparo dos alimentos. Torna-se obrigatório, também, antecipar as tarefas do dia seguinte, usando os períodos vespertinos, quando o trabalho de cocção se reduz. E, se preciso for, as merendeiras se valem ainda do próprio horário de refeição e de descanso.

Ainda que o coletivo de trabalho funcione de modo harmônico, com as merendeiras executando as tarefas que percebem como necessárias naquele momento, devido às condições de trabalho, o corpo das merendeiras não dispõe de momentos de relaxamento e de recuperação da carga de trabalho imposta, resultando, ao longo do tempo, em adoecimento.

A pressão temporal foi uma variável do trabalho percebida desde as primeiras observações gerais. A posterior identificação da densidade do trabalho pela sobreposição de atividades em curto período de tempo e a verificação da não alteração do ritmo de trabalho, uma vez que os tempos observados nas ações continuaram os mesmos, levaram à conclusão de que a atividade, como um todo, está acelerada e intensificada em seu limite extremo, resultando em um trabalho sem porosidade. No período da manhã, por concentrar um número maior de tarefas para serem realizadas em menor espaço de tempo, não há como acelerar mais; no período da tarde, que, em tese, teria um menor volume de tarefas, continua intensificado pela associação de outras tarefas, como o recebimento de mercadorias dos fornecedores, a limpeza do freezer e da geladeira, a limpeza geral da cozinha, bem como pelas tarefas antecipadas.

\section{Recomendações}

O relatório final, apresentado à direção da Merenda Escolar em maio de 2008, contém uma série de recomendações sistematizadas em três grandes categorias de análise.

Para melhoria da organização do processo de trabaIho, sugeriu-se:

- Elaboração de um novo cardápio que articule as refeições da Escola e da Creche e que considere, também como critério, a carga de trabalho das trabalhadoras que vão executá-lo;

- Participação ativa das merendeiras na definição do cardápio;

- Não prescrição dos cardápios de maior grau de dificuldade no seu preparo (macarronada, polenta e cuscuz) para os dias da semana que ocorrem o recebimento de gêneros alimentícios, o controle burocrático mensal, o preparo do tempero, a limpeza do freezer e da geladeira e a limpeza geral da cozinha;

- Disponibilização, pela empresa terceirizada, de uma merendeira volante experiente para auxiliar a equipe no processo de elaboração da merenda escolar nos dias de entrega de gêneros alimentícios pelos fornecedores;

- Constituição de uma equipe externa de faxineiros que se encarregue da faxina geral das cozinhas, no período noturno ou nos finais de semana.

Em relação às condições de trabalho, recomendou-se:

- Instalação de uma máquina de lavar louças modelo industrial, com capacidade para lavar/secar no mínimo 20 pratos/ciclo, com ciclo inferior a 5 minutos;

- Colocação de uma ducha móvel de água quente na cuba de maior profundidade para lavar vasilhames de maior porte;

- Aquisição de facas de melhor qualidade, em tamanhos e formatos adequados às diferentes aplicações;

- Implementação de um esquema regular de manutenção/afiamento das facas, a ser realizado por funcionário designado pela prefeitura;

- Aquisição da carne totalmente processada, ou seja, limpa, cortada ou moída, em conformidade com o cardápio ao qual se destina;

- Aquisição do alho já descascado;

- Desenho e confecção de um novo uniforme, padronizado para todas as merendeiras, quer da prefeitura, quer terceirizadas, considerando critérios de 
uso, conforto térmico, durabilidade e facilidade na lavagem. Durante o redesenho do uniforme, faz-se indispensável a participação das merendeiras.

Estas medidas, se implantadas, no seu conjunto, têm a potencialidade de diminuir a pressão temporal e a sobrecarga física das trabalhadoras.

Quanto às relações de trabalho:

- Possibilitar que durante os momentos dos programas de capacitação anuais seja possível a explicitação das dificuldades vivenciadas no trabalho, a elaboração de soluções e melhorias e a troca de experiências por parte das merendeiras;

- Promover encontros mensais entre as merendeiras, a supervisão da Merenda Escolar e a direção da escola, para colocação das propostas pedagógicas e discussão das implicações ergonômicas no processo de trabalho;

- Participação da representação das merendeiras no Conselho Municipal da Merenda Escolar;

- Mudança via projeto de lei municipal, alterando a denominação do cargo de merendeira para cozinheira;

- Isonomia entre as merendeiras concursadas e as terceirizadas.

\section{Considerações finais}

A transformação da merenda escolar como direito constitucional representou uma conquista de cidadania da nação brasileira, que requer esforços sociais continuados para sua permanência e aperfeiçoamento.

$\mathrm{O}$ acesso universal à alimentação como insumo para a aprendizagem, a garantia da segurança e da qualidade dos alimentos oferecidos, o monitoramento da situação nutricional dos escolares, a prevenção e o controle dos distúrbios nutricionais e das doenças associadas à alimentação e nutrição e a promoção de práticas alimentares saudáveis são princípios e diretrizes que contribuem não apenas para a melhoria do desempenho escolar e para a redução da evasão e da repetência, mas, também ampliam as possibilidades dos municípios em melhorar a saúde de uma parcela significativa da população em idade de crescimento, reduzindo a sua vulnerabilidade social (COSTA; LIMA; RIBEIRO, 2002).

Compreender e valorizar o trabalho das merendeiras, superar suas deficiências e eliminar a ocorrência de agravos à saúde destas trabalhadoras se constitui em importantes estratégias para o alcance dos amplos objetivos nacionais que estruturam esta política pública.

\section{Contribuições de autoria}

Takahashi, M. A. B. C.: participou do trabalho de campo, da elaboração da análise e da redação final do artigo. Pizzi, C. R.: participou do trabalho de campo, da elaboração da análise, da confecção dos gráficos e da redação final do artigo. Diniz, E. P. H.: fez a supervisão do trabalho de campo e participou da elaboração da análise e da redação final do artigo.

\section{Referências}

ASSOCIAÇÃO BRASILEIRA DE ERGONOMIA. Norma ERG BR 1002, Código de Deontologia do Ergonomista Certificado, 2003. Disponível em: <www.abergo.org. br >. Acesso em: 15 jan. 2007.

ASSUNÇÃO, A. A.; VILELA, L. V. O. Lesões por esforços repetitivos - Guia para profissionais de saúde. Piracicaba: Cerest, 2009.

CHILLIDA, M. S. P.; COCCO, M. I. M. Saúde do trabalhador \& terceirização: perfil de trabalhadores de serviços de limpeza hospitalar. Revista LatinoAmericana de Enfermagem, Ribeirão Preto, v. 12, n. 2, p. 271-276, abr. 2004.

COSTA, E. Q.; LIMA, E. S.; RIBEIRO, V. M. B. O treinamento de merendeiras: análise do material instrucional do Instituto de Nutrição Anne Dias - Rio de Janeiro (1956-94). História, Ciências, SaúdeManguinhos, Rio de Janeiro, v. 9, n. 3, p. 535-560, set./dez. 2002.

COSTA, E. Q.; RIBEIRO, V. M. B.; RIBEIRO, E. C. O. Programa de alimentação escolar: espaço de aprendizagem e produção de conhecimento. Revista de Nutrição, Campinas, v. 14, n. 3, p. 1-6, 2001.

FERREIRA, A. B. H. Médio dicionário Aurélio. Rio de Janeiro: Nova Fronteira, 1980.

GUÉRIN, F. et al. Compreender o trabalho para transformá-lo: a prática da ergonomia. São Paulo: Edgar Blücher, 2001.

LIMA, F. P. A. Ergonomia e prevenção da LER: possibilidades e limites. In: LIMA, M. E. A; ARAÚJO, J. N. G, LIMA, F. P. A. LER - Lesões por esforços repetitivos: dimensões ergonômicas e psicossociais, Belo Horizonte: Health, 1997. p. 312-353.

LIMA, F. P. A. et al. A produção das lesões por esforços repetitivos num restaurante universitário: análise ergonômica e psicossocial. In: LIMA, M. E. A; ARAÚJO, J. N. G, LIMA, F. P. A. LER - Lesões por esforços repetitivos: dimensões ergonômicas e psicossociais, Belo Horizonte: Health, 1997. p. 108-177.

NUNES, B. O. O sentido do trabalho para merendeiras e serventes em situação de readaptação nas escolas 
públicas do Rio de Janeiro. 2000. 161 f. Dissertação (Mestrado em Saúde Pública)-Escola Nacional de Saúde Pública, Fiocruz, Rio de Janeiro, 2000.

SILVA, E. F.; BRITO, J.; ATHAYDE, M. Saúde? O drama cotidiano das merendeiras das escolas públicas. In: ENCONTRO NACIONAL DE ESTUDOS DO TRABALHO, 7., 2001, Salvador. Anais... Salvador: ABET: Universidade Federal da Bahia, 2001.

WISNER, A. A inteligência no trabalho: textos selecionados de ergonomia. São Paulo: Fundacentro, 1993.
. Atividades humanas previstas, atividades humanas reais nos sistemas automatizados. In: LIMA, F. P. A.; NORMAND, J. E. Qualidade da produção, produção dos homens: aspectos sociais, culturais e subjetivos da qualidade e da produtividade. Belo Horizonte: UFMG, 1996. p. 1-16.

ZAMBERLAN, C.; SIQUEIRA, H. C. H. A terceirização nos serviços e conseqüências no cuidar em enfermagem. Revista Brasileira de Enfermagem, Brasília, v. 58, n. 6, dez. 2005. 